\title{
A produção de verdades acerca da gramática em práticas discursivas de professores de língua portuguesa
}

\author{
Carmen Brunelli de Moura \\ Universidade Potiguar \\ carmenbm@bol.com.br \\ Marluce Pereira da Silva \\ Universidade Federal da Paraíba \\ marlucepereira@uol.com.br
}

\section{Resumo}

Neste trabalho apresentamos breves reflexões sobre a perspectiva dos docentes de um Curso de Especialização instados em uma das atividades realizadas, a discutirem as concepções de gramática que norteiam suas aulas de Língua Portuguesa Indagamos os professores sobre a forma de orientarem suas práticas frente à taxonomia gramatical que norteia as aulas de português. Objetivamos problematizar a concepção de gramática que constrói sentidos em suas práticas pedagógicas. Analisamos fragmentos de algumas das atividades solicitadas a esses professores e percebemos que, em seu dizer-fazer pedagógico, os docentes adotam tanto práticas originárias da gramática normativa quanto da perspectiva descritiva que orientam o ensino da gramática. Foi possível observar, nessa discursividade, outros posicionamentos que rompem com essa regularidade enunciativa e materializam uma concepção de gramática e de linguagem que privilegia atividades de uso efetivo da língua materna.

Palavras-chave: Gramática e linguagem, Ensino de língua portuguesa, Discursividade.

\begin{abstract}
In this paper we present brief reflections about the perspectives of professors in a specialization course, who were pushed into discussing the conceptions of grammar that guide their Portuguese classes. We questioned these professors about how they direct their practice before
\end{abstract}


the grammatical taxonomy that guides Portuguese classes. We aim to discuss this conception of grammar that builds meanings in their pedagogical practices. We analyzed fragments of some activities that were requested from them and noticed that these professors adopt either normative or descriptive grammar originated practices. Such practices guide the teaching of grammar in their pedagogical statemake. It was also possible to observe in this discursiveness other different attitudes, which break up with this enunciative regularity and which materialize a conception of grammar and language that grants a privilege to activities of effective use of the mother tongue.

Key-words: Grammar and Language, Teaching of Portuguese, Discursiveness.

\section{Introdução}

Não vamos nos demorar muito no limiar da porta, passemos, por conseguinte, ao vestíbulo. Nietzsche

As palavras em epígrafe de Nietzsche nos lembram que as verdades com as quais lidamos no cotidiano de sala de aula são fluidas, incertas, flutuantes. Essas características parecem relevantes quando tentamos articular nossas pesquisas com um tempo em que "nem tudo é verdadeiro; mas em todo lugar e a todo momento existe uma verdade a ser dita e a ser vista" (FOUCAULT, 2003, p.113). Ou seja, não é mais possível fixarmo-nos no limiar da porta à espreita das verdades, esperando que elas venham até nós e nos digam seus propósitos. É preciso pensar a verdade não como algo dado, mas como algo construído historicamente, discursivamente; verdade aqui compreendida como alguma coisa que se suscita. Verdades são acontecimentos que não implicam a busca de causas ou consequências, mas uma procura por singularidades, aberturas, imprevisibilidades, realidades.

Nesse relato de uma experiência vivenciada em sala de aula, refletimos sobre os sentidos de estar presente em uma miríade de acontecimentos entrelaçados com a tarefa de lançarmos um olhar para os discursos produzidos por alunos- 
professores $^{1}$ em uma atividade que fora solicitada, inicialmente, com o propósito de aferir nota à disciplina Teorias e ensino da gramática. Esse alunado pertencia ao Curso de Especialização em Língua Portuguesa: leitura, produção de textos e gramática, da Universidade Federal do Rio Grande do Norte realizado nas cidades de Natal/RN e Nova Cruz/RN, em 2008. A maioria das turmas era composta por docentes de língua portuguesa ${ }^{2}$ das redes pública e privada. As aulas ocorriam aos finais de semana nesses municípios.

Durante as discussões dos textos em sala de aula, a professora percebia que os alunos-professores interessavam-se pela leitura de textos atinentes à teoria e ao ensino de gramática na sala de aula de Língua Portuguesa. A professora apreendia ainda que as discussões dos textos suscitavam inquietações por parte dos alunos-professores, o que poderia traduzir sentidos do quanto o modelo de ensino da gramática que os autores desses textos criticavam também os incomodava.

Enfim, havia uma discursividade em torno de que o ensino da língua deveria ser realizado, segundo o depoimento de alguns docentes, como uma "forma de interação comunicativa". O que reafirmava os sentidos que remetiam ao estudo da gramática para conduzir à "obtenção de maior qualidade de vida" para os usuários da língua, conforme proposto por Travaglia (1999, p. 241). Essa postura dos docentes nos levava a questionar: em que medida os sentidos expressos nesse depoimento se instituem na prática de sala de aula, ou ainda, se todos os alunos do curso adotavam tal posição acerca do ensino da gramática.

Pautada nas discussões dos textos trabalhados ao longo do curso, a professora ministrante solicitou, como atividade final da disciplina, o relato escrito dos alunos-professores de um fato vinculado ao ensino da gramática vivenciado por eles nas respectivas salas de aula de Língua Portuguesa. Para tanto, esses alunos precisariam justificar o fato mencionado com reflexões

${ }^{1}$ Com a denominação alunos-professores ou docentes referimo-nos aos trinta alunos do Curso de Especialização.

${ }^{2}$ Apenas uma docente era graduada em Pedagogia. 
embasadas nos textos teóricos abordados nas aulas do Curso de Especialização. Em meio aos acontecimentos discursivos narrados, houve episódios que chamaram a atenção da professora, pois, ao solicitar tal atividade, ela percebeu que os alunos ficaram muito entusiasmados com a possibilidade que lhes foi dada de relatar suas práticas didático-pedagógicas, a ponto de a convidarem a ouvir suas experiências das aulas de Língua Portuguesa antes de as registrarem por escrito. A maioria deles, ao relatar oralmente as atividades de ensino, antes da produção do texto escrito, mostrou posicionamentos críticos em relação a algumas reflexões suscitadas pelos textos. $\mathrm{Na}$ atividade escrita, a professora esperava encontrar também esses posicionamentos nos textos apresentados. No entanto, para sua surpresa, apenas um relato experienciado constituía ou expressava tal criticidade. Os dizeres no texto escrito não produziam sentidos de práticas discursivas que constituíram subjetividades dos alunos-professores, quando se posicionaram durante as aulas. O que havia era uma regularidade enunciativa, ou seja, pontos singulares aos enunciados, uma "vontade de verdade" (FOUCAULT, 2004) de reconhecer certos discursos, certas verdades, que pareciam inerentes ao contexto escolar e precisavam ser exploradas. Desse modo, poderíamos compreender as condições de formação daquele discurso em relação ao ensino da gramática. No entanto, seria possível descrever outros discursos cujos sentidos rompessem com essa regularidade?

De acordo com Antunes (2003), essa é uma tarefa urgente, uma vez que na sala de aula ainda são recorrentes práticas ancoradas em atividades nas quais o professor faz uso do ensino de uma gramática descontextualizada, fragmentada, irrelevante, excêntrica, inflexível, prescritiva, apoiada em textos artificiais. Como há uma relação intrínseca entre fazer e dizer, a concepção de linguagem também determina as práticas do professor em relação à gramática a ser adotada em sala de aula.

Foi essa orientação apresentada pela autora e a concepção de linguagem e de gramática proposta por Travaglia (1999, 2009), Geraldi (1984) e Neves (2003) que nos levaram a 
olhar para os textos, produzidos inicialmente para nota, para descrever o ponto de vista desses alunos-professores acerca da gramática, o atravessamento ou ponto de articulação com outras concepções de gramática. Ou seja, com base nas perspectivas desses autores sobre o ensino de gramática, conhecer a concepção que perpassa o discurso dos alunos-professores em formação.

É imprescindível enfatizar que além de reafirmar a concepção mais adequada, constitui propósito maior discutirmos o caráter social dos usos da linguagem, no sentido de analisarmos as práticas que orientam professores egressos dos cursos de Letras a se posicionarem quanto ao ensino da gramática.

\section{Concepções de linguagem e de gramática: o que nos dizem os autores}

Para discutirmos o ensino e a concepção (ou concepções) da gramática que produzem sentidos nos textos dos alunos-professores se faz relevante, inicialmente, situarmos as visões de linguagem associadas às práticas de sala de aula de Língua Portuguesa e, consequentemente, ao próprio ensino de gramática. A seguir, conhecer as concepções de gramática que perpassam essas visões e, concomitante a isso, os enunciados retirados dos textos dos alunos que justificam o dizer dos autores (POSSENTI, 1997, GERALDI, 2000, TRAVAGLIA, 2009). Vamos acompanhar os discursos acerca de algumas orientações didáticas que norteiam o ensino de gramática nas escolas de ensino fundamental e médio. Isso porque após a "virada linguística", caracterizada pela reação à unidade entre as palavras e as coisas e à filosofia mentalista, parece-nos impossível ignorar que os discursos não podem ser apenas concebidos como descrição da realidade. Os discursos devem ser apreendidos como constituintes de nossas práticas sociais e, portanto, ao descrever alguém ou algo, é a linguagem que produz essa "realidade" e institui algo. 
Assim, ao lado de outros autores que assinalam o quanto é difícil para os professores propiciarem um ensino eficaz da gramática nas aulas de Língua Portuguesa, Travaglia (2009) apresenta uma tentativa de proposta para o ensino de gramática nas aulas de língua. Para o estudioso, os objetivos delineados pelo professor esbarram numa questão central: "para que se dão aulas de Português a falantes nativos de Português?". Nessa direção, também se configura como questão proeminente a concepção que os professores atribuem à língua e à linguagem, uma vez que tal compreensão irá definir como o docente organizará suas aulas de língua portuguesa, sobretudo o ensino da gramática.

De acordo com vários autores (POSSENTI, 1997, GERALDI, 2000, TRAVAGLIA, 2009), há três possibilidades de se conceber a linguagem, a saber: i) a linguagem como expressão do pensamento; ii) a linguagem como instrumento de comunicação e iii) a linguagem como forma ou processo de interação. Na primeira concepção, a relação entre o sujeito e a linguagem resume-se em uma atividade monológica na qual o objetivo principal do sujeito é apropriar-se das regras que traduzam seus pensamentos de forma lógica. Desse modo, contextos e intersubjetividade são indiferentes, estão apenas justapostos, uma vez que a linguagem é concebida como um sistema fechado.Enquanto, nesta concepção, evidenciam-se efeitos de fala e de escrita ideais e bem estruturadas, na segunda concepção - a linguagem como instrumento de comunicação -, corroboram efeitos de uma linguagem como instrumento de comunicação entre sujeitos que devem ter em comum uma língua e serem capazes de utilizá-la para transmitir mensagens e também para decodificá-la. No entanto, nessa relação entre pelo menos dois sujeitos não se constitui em interação, uma vez que os falantes são afastados do uso efetivo da língua. Ou seja, a finalidade da linguagem como comunicação é a transmissão de uma mensagem de um emissor para um receptor. Novamente há uma atividade monológica, pois os falantes são deslocados do processo de produção da língua e, consequentemente, de tudo que é social e histórico. 
Quanto à terceira concepção, Travaglia (2009) aponta que a linguagem como processo de interação deveria estar presente nos discursos dos professores e em suas práticas em sala de aula, uma vez que, nesta, a intenção não está mais na exteriorização do pensamento nem na transmissão de mensagens. O interesse agora é com a realização de ações entre sujeitos falantes de uma língua que tentam convencer seus interlocutores de uma verdade. É a linguagem como um lugar de interação, de criação, de transformação, no qual os sujeitos se posicionam, inventam-se e reinventam novas subjetividades.

Ao concebermos a linguagem como um processo, um "movimento em constante fluxo" (SILVA, 1994, p. 249), entendemos que as concepções de linguagem como expressão do pensamento e instrumento de comunicação já não são suficientes para dar conta dos sentidos produzidos entre interlocutores nas práticas sociais em que se inserem. Do mesmo modo, são as aulas de ensino da gramática que se pautam nessas concepções e evidenciam verdades instituídas por poderes totalizadores. O ensino deve se ancorar em verdades cujos significados "não expressam, nas suas diferentes concepções, aproximações a um suposto 'correto', 'verdadeiro', 'melhor'”, conforme Costa $(1998$, p.41) ou sobre a manutenção de uma dicotomia entre certo e errado. Essa dicotomia não se constitui uma proposta anticientífica e antinatural em relação ao uso da gramática, mas em um jogo discursivo e interacional que desenvolva as competências dos sujeitos.

É nesse sentido que pretendemos apreender que concepção de linguagem e, consequentemente, de gramática, perpassa o discurso desses alunos-professores, pois o modo como o professor concebe a linguagem implica no direcionamento de sua prática na sala de aula. Nada mais coerente que começar pelo óbvio, segundo afirma Possenti (1997):

[...] se não para ensinar gramática, pelo menos para defender tal ensino, é preciso - ou parece decente que seja assim - saber o que é gramática. Acontece que a noção de gramática é controvertida: nem todos os 
que se dedicam ao estudo desse aspecto das línguas a definem da mesma maneira. (POSSENTI, 1997, p.63)

Assim, como há três concepções de linguagem e essas direcionam a prática do professor, com a gramática não é diferente. Travaglia (2001) argumenta que a metodologia utilizada pelo professor está intimamente relacionada com aquilo que o docente entende por ensino da gramática e pelo modo como ensina a gramática. E acrescenta que essas concepções geram certo conflito na vida do professor, pois ele se percebe entre um saber prescritivo imposto pela gramática e um saber descritivo-produtivo gerado pelos estudos linguísticos.

É necessário que o professor compreenda que toda língua tem uma gramática e, para compreender o uso que os falantes fazem de sua língua, é igualmente necessário definir o melhor modo de estudar a gramática a fim de que a escola não crie "[...] no aluno a falsa e estéril noção de que falar e ler ou escrever não tem nada que ver com gramática" (NEVES, 2000, p.52). Também não é possível atrelar o ensino da gramática ao "[...] ensino de metalinguagem, de teoria gramatical ou linguística desenvolvido por meio de atividades de gramática teórica" (TRAVAGLIA, 2011, p. 94), pois esta prática dificilmente desenvolveria a competência comunicativa dos sujeitos. Sobre isso Neves, em entrevista ao jornal UNESPCIÊNCIA, de dezembro de 2009, afirma que a gramática não se constitui em um aglomerado de regras nem na decoreba dessas regras. A gramática é linguagem em funcionamento e produção de sentidos.

Para tentar compreender esses pensamentos, passaremos a elucidar as concepções de gramática com base em uma discursividade (TRAVAGLIA, 2009; POSSENTI, 1997; FRANCHI, 1991) que evidencia efeitos de correntes tradicionais, estruturalistas e gerativistas e enunciativas, para tentar demonstrar aspectos singulares entre essas concepções e as implicações destas nas visões de linguagem..

Na primeira concepção, a gramática é concebida "como um manual com regras de bom uso da língua a serem seguidas 
por aqueles que querem se expressar adequadamente" (TRAVAGLIA, 1996, p.111). Nesse sentido, saber gramática implica reconhecer normas prescritas por especialistas e seguidas pelos sujeitos que devem dominá-las para falar $e$ escrever bem a norma culta. As outras variedades da língua não são consideradas ou são analisadas como "erradas" ou desprestigiadas socialmente. Assim, “[...] a língua é só a variedade dita padrão ou culta e que todas as outras formas de uso da língua são desvios, erros, deformações, degenerações [...]" (TRAVAGLIA, 2001, p.26). Decorre daí uma tendência entre professores que é a produção de práticas ancoradas na prescrição de normas que devem ser assimiladas pelos alunos para eles se comunicarem mais adequadamente.

Nessa perspectiva, a gramática normativa é concebida como algo definitivo e acabado que legitima verdades instituídas por uma classe social de prestígio na sociedade a serem seguidas por todos. Embora os estudos linguísticos venham cada vez mais ocupando espaços antes destinados aos estudos tradicionais, as práticas pautadas no jogo entre o que é gramatical e não gramatical ainda se fazem presentes na sala de aula e se distanciam do texto, considerado objeto de estudo pelos Parâmetros Curriculares Nacionais (PCN) de Língua Portuguesa.

A outra concepção de gramática é designada de descritiva por delinear o funcionamento da língua e sua estrutura. Essa gramática foi produzida com base nas teorias estruturalistas, nas quais há privilégio da descrição, e a gerativotransformacional, que aponta para os enunciados ideais produzidos por um falante-ouvinte também ideal. Conforme Travaglia (2009, p. 27), esta concepção se baseia em um "conjunto de regras que o cientista encontra nos dados que analisa, à luz de determinada teoria e método".

Quanto à terceira concepção, Travaglia (2009, p.28) argumenta que é uma gramática que o usuário da língua percebe como um "conjunto das regras que o falante de fato aprendeu e das quais lança mão ao falar”. É a gramática que não depende da sistematização e apreensão de regras impostas por um segmento da sociedade, mas do reconhecimento de que saber a gramática de uma língua é saber utilizá-la em situações reais. Portanto, a 
gramática internalizada implica competência gramatical, textual e discursiva dos usuários de uma língua. Essa concepção de gramática indica a noção de linguagem como prática social, de natureza discursiva, e o estudo que não dissocia estrutura linguística e história e que busca compreender os usos da língua em determinados contextos.

Tentaremos ilustrar como essas concepções se materializariam nos discursos dos alunos-professores.

\section{Ensino de gramática: a visão dos alunos-professores}

Após a realização das atividades na sala de aula, a professora ministrante da disciplina solicitou aos alunosprofessores que produzissem um texto. Dele, procedemos recortes de enunciados que ilustrassem a reflexão aqui proposta sobre ensino de gramática e sobre o modo como esses alunosprofessores se posicionam acerca do ensino de gramática. A experiência vivenciada por uma aluna-professora ocorreu em uma sala de aula de uma turma do $8^{\circ}$ ano na qual ela ministrava o conteúdo gramatical "orações sem sujeito". Após as explicações em torno das regras gramaticais dadas por essa docente à turma, um aluno manifestou-se contrário sobre à inexistência do sujeito no enunciado: "Há alunos na fila da cantina". O aluno afirmou, com veemência, que havia um sujeito representado pela expressão "os alunos". No seu relato, a docente revela que se muniu da orientação gramatical para tentar convencer o seu aluno da classificação do sujeito.

A aluna-professora, pautada em prescrições gramaticais, argumenta para o seu aluno que o "verbo haver" não possuía um sujeito, pois aquele termo estava colocado no enunciado com o sentido de existir e, depois, que não haveria um termo com o qual o verbo pudesse concordar; logo, não haveria sujeito. No entanto, novamente, os dizeres da professora não convencem o aluno que continua não aceitando tal classificação. É nesse momento que ela define a concepção de gramática norteadora de sua prática docente, quando relata: 
[...] ao ver que ele continuava sem aceitar, eu recorri à gramática que muito ajudou quando explica que o verbo deve flexionar em número e pessoa para concordar com o termo ao qual se refere. Logo, a gramática normativa ajudou muito na justificativa da impessoalidade do verbo no contexto citado, porém, o aluno não aceitou e não se convenceu (grifos nossos).

A concepção de gramática adotada pela docente traduz sentidos de outros já-ditos, numa compreensão de que as regras da língua não podem ser questionadas. Seus usuários devem seguir suas regras, pois são elas que propiciam a todos expressarem-se adequadamente. Descrita como gramática normativa, a professora nega a heterogeneidade linguística, uma vez que, em sua orientação didática, não atribui qualquer relevância ao uso que o aluno faz da língua ou da oralidade. É notável o quanto esta concepção de gramática é legitimada em discursos dos professores de Língua Portuguesa e presente também na situação aqui narrada. No seu relato, a docente afirma não conseguir convencer o aluno apenas com suas explicações orais durante a aula, mas sim quando recorre à gramática normativa que "muito" a ajudou a explicar a impessoalidade do verbo "haver" questionada pelo aluno.

No entanto, a aluna-professora parece apreender o quanto o ensino prescritivo não responde satisfatoriamente aos questionamentos de seu aluno e menos ainda que esta atividade irá permitir ao aluno desenvolver sua competência comunicativa. A concepção de ensino da gramática deve levar em consideração que, se o aluno não aprender a utilizar adequadamente os recursos da língua em diferentes interações comunicativas, consequentemente, isso trará implicações para a melhoria de sua qualidade de vida, visto que o falante que tem a possibilidade de se posicionar nas relações sociais, provavelmente estará apto a entender as estratégias argumentativas, significativas e de relação social e cultural instauradas no seu falar (TRAVAGLIA, 1999). A professora 
parece perceber também que a gramática, que "muito a ajudou na sua explicação," não alcançou êxito junto ao aluno que "não aceitou e não se convenceu", o que justifica a ineficácia de um ensino gramatical desarticulado de uma concepção de linguagem como prática social. Conforme afirma outro aluno-professor do Curso "[...] a gramática existe não em função de si mesma, mas em função do que as pessoas falam, ouvem, leem e escrevem nas práticas sociais de uso da língua".

Retomemos a concepção de gramática denominada descritiva, por se preocupar em fazer "uma descrição da estrutura e funcionamento da língua" (TRAVAGLIA, 1996, p.112). Nessa concepção, há o reconhecimento de variedades linguísticas e, diferentemente da primeira concepção, o objetivo é descrever as formas possíveis de utilização da língua para a comunicação entre seus falantes. Os efeitos de sentido produzidos pelas sequências discursivas nesta concepção devem ser levados em consideração, uma vez que o léxico em suas várias realizações na língua não é estável, regular. Como diz Foucault (2004b), os enunciados podem ser idênticos do ponto de vista gramatical e estrutural, mas são enunciativamente diferentes, pois uma "frase não constitui o mesmo enunciado se for articulada por alguém durante uma conversa, ou impressa em um romance; se for escrita um dia, há séculos, e se reaparece agora em uma formulação oral" (FOUCAULT, 2008, p.113).

Na tentativa de continuar compreendendo as concepções de gramática que subjazem os discursos dos alunos-professores em seus textos, parece-nos que essa concepção de gramática perpassa muitas experiências. E o texto de um desses docentes chamou nossa atenção por apresentar sentidos que parecem seguir uma direção contrária ao relato aqui analisado. Esse docente inicia sua reflexão afirmando que:

[...] é comum surgirem dúvidas em relação às questões de uso e aplicação das regras gramaticais, uma vez que há uma disparidade entre a gramática internalizada e as regras estabelecidas segundo a norma padrão. 
Neste excerto já é possível compreender uma discursividade que traduz sentidos em torno da apropriação de uma concepção de gramática que vai além da normativa, pois o docente declara que se o professor não se equipar de outros conhecimentos acerca do ensino da gramática, serão frustradas suas tentativas de tentar responder aos questionamentos dos alunos conforme relatado na experiência anterior. Dado esse mote em sala de aula, a reflexão acerca dos usos da Língua Portuguesa e sobre a sua "gramática" caminhou para o entendimento de que ensinar regras que devem ser seguidas é uma atividade diferente de ensinar regras que podem ser seguidas, dependendo dos usos e das situações comunicativas.

$\mathrm{E}$ isso parece estar bem evidente para o aluno-professor quando inicia sua reflexão acerca dos "verbos de ligação" que são descritos na gramática normativa como: ser, estar, permanecer, ficar, continuar, tornar-se e parecer. Essa classificação, segundo declarações de um dos docentes, não esclarece e tampouco acata as expectativas dos alunos a respeito da utilização desses verbos em situações específicas. $\mathrm{O}$ excerto exemplifica o questionamento de um aluno de uma turma do $8^{\circ}$ ano a respeito do verbo "ficar". Segundo o dizer de um dos docentes em seu texto:

[...] o verbo é citado nas gramáticas normativas como verbo não significativo, ou seja, de ligação e por isso não expressaria "ação", como se explica na frase: "Carlos ficou com a minha prima".

Para responder aos questionamentos do aluno, o docente não teve como referência a gramática normativa como, em geral, alguns professores fazem. Ele revelou, em sua prática, que não existe uma única variedade de língua, e que esse ponto de vista parece não se sustentar mais em uma sala de aula. O docente, ao contrário, procurou mostrar ao aluno que há outros modos de ensinar e aprender e que não precisam reproduzir a clássica metodologia da definição, classificação, mas que há "outros sentidos para o verbo ficar (namorar), em que ele funciona como 
ação e sua classificação diverge dos conceitos da gramática normativa", conforme explica o professor.

Vemos, portanto, que esse docente elabora sentidos em seu relato atravessados por uma prática orientada pela gramática descritiva, pois ele busca mostrar ao aluno não apenas a existência de uma variedade linguística, mas também de outras variedades, utilizadas em outras práticas sociais e que são imprescindíveis para sua mobilidade social. É possível apreender nos discursos desse docente que ainda não abandona as prescrições da gramática normativa, visto que ele declara que o verbo "ficar" com sentido de namorar tem outra "classificação" que não se encontra na gramática que traduz a língua padrão. A posição que o aluno-professor assume nesse momento indica um regime de verdade (FOUCAULT, 1985) que está atrelado a poderes que passam a controlar, regular, apoiar uma política geral de verdade (FOUCAULT, 1985) que ratifica alguns discursos e os faz funcionar como verdadeiros em certas situações. A prática desse docente parece reproduzir uma metalinguagem ao assumir os procedimentos impostos por essa visão de linguagem e de gramática.

A atitude desse docente não é única. Neves (2003), com o propósito de investigar que concepção o professor tem da gramática da língua e a partir dela definir o que deve ser "ensinado ou exercitado", lança mão da seguinte pergunta "para que você ensina gramática?", direcionada a professores.

A pesquisadora afirma que conseguiu depreender das respostas dos professores dois conceitos em torno da gramática:

1. Gramática como um conjunto de regras de bom uso (gramática normativa).

2. Gramática como descrição das entidades da língua e suas funções (gramática descritiva).

O que reflete, segundo Neves (2003), que nenhum professor revelou conceber a gramática como um sistema de regras da língua em funcionamento. Essa concepção é descrita por Travaglia (1996) como conjunto de variedades utilizadas por uma sociedade e está associada à terceira concepção de gramática proposta por ele e denominada de internalizada. Essa 
gramática consiste em um saber não escolarizado e é por meio dela que o falante constrói um número infinito de frases. Essa concepção perpassa o discurso dos PCN ao ser afirmado:

[...] as escolhas feitas ao dizer, ao produzir um discurso, não são aleatórias - ainda que possam ser inconscientes -, mas decorrentes das condições em que o discurso é realizado. Quer dizer: quando um sujeito interage verbalmente com outro, o discurso se organiza a partir das finalidades e intenções do locutor, dos conhecimentos que acredita que o interlocutor possua sobre o assunto, do que supõe serem suas opiniões e convicções, simpatias e antipatias, da relação de afinidade e do grau de familiaridade que têm, da posição social e hierárquica que ocupam. (BRASIL, 1998, p.21).

Essa relação que os sujeitos estabelecem entre si, e que se traduz na proposta dos PCN, implica que tais sujeitos façam escolhas e produzam efeitos de sentidos que correspondem aos momentos de rupturas, ressignificações, de uso efetivo da linguagem, de posicionamento, de endereçamento, de negociação. Nessa concepção de gramática internalizada, existe a possibilidade de o professor fazer escolhas em relação às regras a serem seguidas sem que este se submeta ou assujeite-se a concepções fechadas. A gramática internalizada traduz sentidos em torno da dimensão ética e de responsabilidade do professor, quando propicia um trabalho em sala de aula. E este é um trabalho de "ativação e amadurecimento progressivo (ou da construção progressiva), na própria atividade linguística, de hipóteses sobre o que seja a linguagem e de seus princípios e regras" (TRAVAGLIA, 1996, p. 113).

Ao observarmos o corpus, notamos que nossos alunosprofessores ainda confirmam a pesquisa realizada por Neves (2003), mas já é possível entrever um discurso de verdade como acontecimento (FOUCAULT, 2004), entendido como um rompimento com as evidências e do qual emergem liberdades, deslocamentos, iniciativas, pensamentos e atuações diferentes. Ou seja, um discurso cujos sentidos expressam mais abertura, 
uma outra realidade, uma singularidade que decorre da utilização dessa concepção de gramática e do questionamento das lacunas existentes nas práticas com as outras duas concepções. Este é o caso de uma professora-aluna do Curso de Especialização que relata episódios ocorridos e decorrentes da adoção por parte da docente de um "método da gramática pela gramática".

No primeiro episódio, a docente narrou que preparava seu material na sala de professores e, para isso, ela tirava cópias de um artigo publicado na revista Veja com o propósito de trabalhar sequências argumentativas com alunos do $3^{\circ}$ ano do Ensino Médio. Ela afirmou que seu propósito era produzir atividades em sala de aula que permitissem aos alunos um trabalho com e sobre a linguagem. A natureza dessa prática para o ensino da gramática deveria auxiliar, segundo a docente, os alunos a compreenderem e a fazerem uso da língua materna de maneira mais eficaz e contextualizada, em práticas efetivas de uso da língua.

O professor de História, que trabalhava também nessa turma, olhando para o material mencionado, afirmou que esse tipo de atividade era "enrolação" da docente. Talvez, por ignorar que existem outros tipos de ensino da gramática, é que o acontecimento dessa fala do professor tenha sido possível. Em outra ocasião, uma aluna-professora relatou que ocorreu fato semelhante, mas este se deu em sala de aula com alunos da graduação. Ao realizar um trabalho sem a observância às regras gramaticais, foi questionada por seus alunos a respeito dessa postura. Os alunos reivindicavam o estudo do "uso das dez classes gramaticais até a sintaxe e suas classificações". Mas a docente revelou que conseguiu convencê-los de que também "precisavam ver a gramática como recurso para escrever e analisar textos e não apenas como nomenclatura para suas determinadas classificações". Ao fazer os seus alunos refletirem sobre o uso da gramática, a aluna-professora abandona $\mathrm{o}$ "conforto" propiciado pela gramática normativa e descritiva e se lança em um campo um tanto desconhecido, uma vez que essa 
prática ainda é rara para a compreensão de tal estudo. Há apenas suposições para os fatos da língua.

Assim, a não aceitação daqueles que não seguem as regras impostas pela gramática normativa nem os enunciados ideais da gramática descritiva sugere ser uma atitude que passa à margem da sala de aula dessas duas alunas-professoras. Haja vista que os relatos delas produzem sentidos que traduzem uma postura diante do ensino da gramática na sala de aula que poderá permitir aos alunos desenvolver a competência comunicativa e compreender o uso dos recursos linguísticos e a adequação deles às situações de uso.

\section{Para concluir}

Concluir talvez não seja a expressão mais acertada para pôr fim à análise de alguns textos dos alunos-professores que figuram nesse relato, uma vez que a discussão acerca do ensino da gramática da Língua Portuguesa não é algo que se deva dar por concluída. Ressaltamos que, ao buscarmos problematizar questões voltadas para o ensino da gramática, nossa intenção não se limitava à constatação de um sentido de verdade hegemônico nos discursos dos alunos-professores em relação à gramática. Ao contrário, sabíamos que, pela própria heterogeneidade dos sujeitos presentes neste Curso de Especialização, haveria algo mais, e esse algo mais seria "uma verdade talvez adormecida, mas que, no entanto, está somente à espera de nosso olhar para aparecer, à espera de nossa mão para ser desvelada" (FOUCAULT, 2003, p.113).

Esse desvelamento produz sentidos acerca do uso da gramática como um acontecimento, pois embora a maioria dos relatos dos professores esteja voltada para práticas que têm como base a gramática normativa ou prescritiva, é possível observar uma ruptura nas evidências e nos consensos que se apoiam em verdades. A exemplo daquelas que não reconhecem o papel de protagonista do professor nas práticas de sala de aula de Língua Portuguesa, voltadas para a concepção de língua em 
funcionamento. É preciso problematizar a imposição de uma mesma verdade a todos aqueles que lidam com a língua.

Portanto, nesse entrelaçamento de acontecimentos, é possível entrever, no outro lado da fronteira, uma janela que se abre para a mudança, para outra prática em que o professor amplia seus conhecimentos para além da concepção da "gramática como norma-padrão", detentora de uma só verdade, em relação à língua, e de um ensino de gramática que privilegia algumas variedades a serem descritas em detrimento de outras. Essa prática tem como preocupação atividades que resultam de reflexões desenvolvidas com base situações reais de uso da língua, imprescindíveis para a qualidade de vida do alunado. Conforme afirma um docente do curso, a "gramática não deve ser ensinada como fim em si mesma", mas deve dar condições para que o aluno amplie seu léxico, aperfeiçoe seu desempenho comunicativo e, consequentemente, quanto maior for o domínio dos mecanismos e recursos da língua, maior será sua mobilidade social e sua competência discursiva.

\section{Referências}

ANTUNES, Irandé. Aulas de português: encontro \& interação. 2. ed. São Paulo: Parábola, 2003.

BRASIL, Ministério da Educação. Secretaria de Educação Fundamental. Parâmetros curriculares nacionais: língua portuguesa. Brasília, 1998.

COSTA, Marisa V. O currículo e a política cultural. In: (Org.). O currículo nos limiares do contemporâneo. Rio de janeiro: DP\&A, 1998. p.37-68.

FOUCAULT, Michel. Verdade e poder. In: Microfísica do poder. 18. ed. Rio de Janeiro: Graal, 2003. p.1-14. 
A casa dos loucos. In: Microfísica do poder. 18. ed. Rio de Janeiro: Graal, 2003. p.113-128. . A ordem do discurso. 10. ed. São Paulo: Loyola, 2004. . A arqueologia do saber. 7. ed. Rio de Janeiro: Forense Universitária, 2008.

FRANCHI, Carlos. Mas o que é mesmo "gramática"?. In: LOPES, Harry V. et al (Orgs). Língua portuguesa: o currículo e a compreensão da realidade. São Paulo, Secretaria da Educação/Coordenadoria de Estudos e Normas Pedagógicas, 1991.

GERALDI, João W. Concepções de linguagem e ensino de português. In: . (Org.). O texto na sala de aula. 2. ed. Cascavel, PR: Assoeste, 1984. p. 41-48.

NEVES, Maria Helena M. A gramática: conhecimento e ensino. In: AZEREDO, José Carlos (Org.). Língua Portuguesa em debate: conhecimento e ensino. Petrópolis: Vozes, 2000. p. 5273.

. Gramática na escola. São Paulo: Contexto, 2003.

- Em defesa de uma gramática que funcione. Unespciência, p. 6-9, dez. 2009. Disponível em: $<$ http://www.unesp.br/aci_ses/revista_ unespciencia/acervo/04/perfil> Acesso em: 2 dez. 2011.

POSSENTI, Sírio. Por que (não) ensinar gramática na escola. Campinas: Mercado de Letras, 1997.

SILVA, Tomas Tadeu. Adeus às metanarrativas educacionais. In:____ (Org.). O sujeito da Educação: estudos foucaultianos. Petrópolis: Vozes, 1994. p. 247-258.

TRAVAGLIA, Luiz Carlos. Ensino de gramática numa perspectiva textual-interativa. In: AZAMBUJA, Jorcelina Q. 
(Org.). O ensino de língua portuguesa: $2^{\circ}$ grau. Uberlândia: EDUFU, 1996. p.107-156.

- Ensino de gramática em uma perspectiva textualinterativa e qualidade de vida. In: HILGERT, José G. et al (Org.). Formando uma sociedade leitora. Passo Fundo, RS: EDIUPF, 1999. p. 237-242.

— Gramática e interação: uma proposta para o ensino de gramática. 11. ed. São Paulo: Cortez, 2006.

2011.

. Gramática: ensino plural. 2. ed. São Paulo: Cortez,

Recebido em: 30/06/2012

Aceito em: 18/02/2013

Title: The production of truths about grammar in discursive practices of professors of Portuguese 